\title{
The evolution of foraminiferal calcification
}

\author{
LENNART J DE NOOIJER, LAURA PACHO SAMPEDRO \\ AND GERT-JAN REICHART
}

NIOZ-Royal Netherlands Institute for Sea Research

Presenting Author: lennart.de.nooijer@nioz.nl

Foraminifera are known to build a wide variety of shells. Some species produce no hard shell at all, but the majority form a one composed of proteins (e.g. most allogromids) or by agglutinating particles together (e.g. textullariids). The remaining groups are those used in paleoceanographic studies since their shells consist of calcium carbonate and hence preserve relatively well. Moreover the chemical and isotopic composition of this carbonate is often used to reconstruct past environments. Calcification in these foraminifera has evolved multiple times over geological history independently, which explains the large differences in morphology, elemental partitioning, stable isotope fractionation and microstructures between groups. Here we present an overview of Rotalliid, Lagenid, Spiriilinid and Milliolid shell chemistry, including $\mathrm{Mg} / \mathrm{Ca}$, within this context. Differences between these groups are related to shell morphology and microstructures and are most likely also related to differences in biomineralization strategy. Within each of these groups, for example between families within the Rotallids, differences in shell chemistry likely reflect more gradual evolution of a basic common calcification mechanism within such a group. Identifying the flexibility of calcification mechanisms across taxonomic levels, and also at a smaller level, is a way to determine whether modern-day proxy-calibrations can extrapolated into the past and potentially even to extinct species. Moreover, it emphasizes the added value of using multiple taxa simultaneously in paleo-reconstructions as this allows to separate the impacts of biomineralization and changes in the environment. 